\title{
Research on Internal Control of Accounting Information System in ERP Environment
}

\author{
Jun FENG \\ Wuhan Business University, Wuhan, 430050, China \\ E-mail: fengjun7608@126.com
}

Keywords: ERP; Accounting information system; Internal control

\begin{abstract}
In recent years, our country has put an unprecedented premium on studies pertaining to internal control, and published a succession of regulations and guidelines, promoting the construction and improvement of internal control within enterprises and institutions. Nevertheless, it is an undeniable and objective fact that the overall internal control of the accounting information system in our domestic enterprises is still weak. Accounting information quality can only be guaranteed under effective internal control, not least under the ERP environment. To this end, this paper aims to: research on the theories regarding the internal control of accounting information system befitting the ERP environment on the basis of both domestic and international theories of the internal control of accounting information system; integrate ERP and internal control, namely urge ERP to constantly draw lessons from the ideas of internal control and in turn prompt internal control to continually adopt ERP's accurate control methods, so as to provide constructive suggestions for the perfection of corporate internal control.
\end{abstract}

\section{Introduction}

Internal control of accounting information system arises with the corporate accounting information system. In 1936, American Institute of Certified Public Accountants officially adopted the technical term "internal control" for the first time in its proclamation of Examination of Financial Statements by Independent Public Accountants. The proclamation defined internal control as the various means and approaches employed within the enterprise for the sake of safeguarding corporate cash and other assets as well as ensuring the accuracy of the accounting records. By virtue of computers, accounting data processing could be accelerated, the accuracy and reliability of accounting could be substantially enhanced and inadvertent errors and miscalculations could be reduced. Nonetheless, ERP's employment could also render the internal control of the accounting information system more intractable, thus causing people to worry about the quality of the series of information produced by the accounting information system. Therefore, it is the starting point of this paper to research on how enterprises could establish the internal control system of accounting information system under the ERP environment in order to improve and update the internal control of accounting information system within our domestic enterprises and to counter the challenges confronting them.

\section{Accounting information system and ERP}

A. The concept of accounting information system

In 1966, A Statement of Basic Accounting Theory published by American Accounting Association explicitly referred accounting as an information system, indicating that "accounting is a process of appreciating, calculating and transmitting information for the sake of facilitating well-founded judgment and decision by information users”. Accounting information system refers to the information management system that utilizes accounting information to glean, store, process and report accounting data. American scholar Bodnar put forward the definition of accounting information system in his Accounting Information System written in 2002: accounting information system is an internet-based system that transforms accounting data into accounting information. But 
we use this concept in a more extensive way so as to make it comprise educational processing cycle, the employment of information technology and the development of information system. Zhang Ruijun and Yang Zhounan suppose that: accounting information system is a valuable-information-oriented system; it is also an information system that makes informational demand from the perspective of reflecting and monitoring the value movement of the institution, namely a system that employs information technology to glean, store and process accounting information and to accomplish accounting task, and that could provide auxiliary information for the accounting management, analysis and decision-making. Amid an information-based society, the regular and programmable tasks in accounting will be dealt with by the accounting information system which will also assist accountants to accomplish other managerial and decision-making tasks.

B. Definition of ERP

ERP is also referred to as Enterprise Resource Planning. It is a whole set of standards for the corporate management system put forth in mid 1990s by Garnter Group Inc.—a renowned American group specializing in computer technology counseling and assessment. It is in essence a managerial idea oriented towards supply chain which is developed on the basis of MRP II. Its concept could be comprehended from the three levels of management idea, software product and management system:

a. ERP is a management idea.

(1) the core management idea of ERP system is to realize integrated management of the overall supply chain resources. (2) ERP is a management philosophy that demonstrates lean production, concurrent engineering and agile manufacturing. (3) ERP is an idea of prior planning and in-process control in corporate operation.

b. ERP is a software product.

ERP comprehensively utilizes client/serve computing, relational database structure, object oriented technology, graphical user interface, 4GL, network communication and other achievements in information industry. It is a software product with ERP's management idea at its core. It is arguable that ERP is an epitome of present-day management software.

c. ERP system.

ERP integrates corporate management philosophy, business procedure, data base, manpower and material resources, hardware and software. It is a corporate information management system that integrates real-time information from different regions, departments and companies.

\section{Factor analysis of internal control of accounting information system amid the ERP environment}

This paper, in accordance with Standards for Corporate Internal Control-Basic Standards (Draft) (2007) and Specific Standards for Corporate Internal Control-Internet Information System (Draft) (2007), carries out the factor analysis of internal control of accounting information system amid the ERP environment, and implement the countering measures for internal risk control of accounting information system amid the ERP environment.

A. Internal environment

Internal environment is a generic term for the various internal factors that influence and constrain the establishment and implementation of corporate internal control. It is the foundation for the implementation of internal control. Internal environment primarily comprises management structure, organization setup and distribution of rights and responsibilities, corporate culture, human resource policies, internal auditing organization setup, anti-fraud mechanism and so forth.

ERP system transforms the corporate internal environment as well as optimizes and redesigns the original business procedures, thus transforming the original organization structure within the enterprise. Under the traditional environment, the fragmented business system in the enterprise generally operates in accordance with some particular function or functional department, exemplified by sales system, procurement system or financial system, etc. Under the ERP 
environment, the enterprise would operate in line with some particular procedure and business module. ERP system makes possible not only the comprehensive integration of procurement, payment, order acquisition, receipt provision and other businesses, but also the business management that transcends the borders of functional departments. It demolishes the original barriers between different functional departments, contributing to the unified management and sharing of corporate resources. Under the ERP environment, corporate business becomes stylized, decision makers and executives could communicate with each other with rapidity, the corporate internal control levels are significantly fewer, controlling responsibilities are more definite, and the control efficiency is improved. The implementation of ERP also changes the methods of internal control and the management ideas in the enterprise. The application of ERP enhances the flexibility of the corporate internal control, and the equivalent channel renders information-wherever it is - readily accessible to personnel both inside and outside of the enterprise. In the meantime, amid the late-model organizational structure of flat type, leaders are no longer merely at the upper strata of the organizational hierarchy, but also become the center of action. To some extent, it is now the ERP system that manages and controls the corporate operation. As the corporate culture that influences the ideas of internal control, it puts a primary emphasis on the overall values such as innovation, cooperation, team administration. Employees' professional integrity and quality should be improved. Corporate leaders ought to discern cohesion and construct organizations in a dynamic environment which should not only contribute to innovation and cooperation, but also reinforce the centripetal force of internal control. Human resource policies are key factors influencing corporate internal environment. Thus the management of department staff should transform from rigid one to flexible one, and the employee evaluation indicator system and incentive mechanism should be more comprehensive and scientific.

B. Risk assessment

Risk refers to the uncertainties that could possibly exert negative influence on the realization of internal control targets. Risk assessment is a process of promptly recognizing, scientifically analyzing and evaluating the various uncertainties that influence the realization of the internal control targets in the enterprise and of carrying out countering measures. It is a crucial part of implementing internal control. Risk assessment primarily comprises goal setting, risk identification, risk analysis and risk response. This paper deems that the goals of the internal control of accounting information system amid the ERP environment include: abide by the laws of the country as well as the rules and regulations of the enterprise; employ internet information technology to regulate the financial data amid the ERP environment, as well as to guarantee the reliability, stability and security of the financial information and the integrity and accuracy of the data; improve the efficiency of the system, decrease the probability of the internal control of accounting information system becoming invalid due to human factors, develop proper information communication between the accounting information system and other sub-systems, and keep the risks in the accounting information system amid the ERP environment at acceptable levels. In terms of the accounting information system amid the ERP environment, even though the overall goals of the enterprise has never changed, with the transformation of the business procedures, the system's availability, information's nature of distribution and data's nature of sharing substantially transform the former operation environment featuring restriction and concentration, thus changing the traditional contents and methods of risk control.

Accounting information system amid the ERP environment combines the information technology of ERP system with accounting activities in an appropriate way to forge the tool of risk prevention. This will greatly reduce mistakes and lapses, ensuring the normal proceeding of corporate businesses. Nevertheless, this also brings about new perils for the enterprise.

C. Control measures

Control measures refer to the means and methods adopted by the enterprise to guarantee the realization of the internal control targets in accordance with the risk assessment outcomes and the risk response strategies. Enterprises should utilize control measures in a comprehensive way to take control of specific businesses and items and undertake to keep the remaining risks at acceptable 
levels. This can guarantee the realization of the internal control targets in the enterprises.

In establishing and implementing the internal control institutions of internet information system, enterprises should at least strengthen their risk control of the following key aspects or parts and take corresponding control measures: (1) the distribution of rights and responsibilities and the division of functions should be definite. Major items in information system should be subject to the examination and approval procedures; (2) the procedures of the development, modification and maintenance of information system should be clear and the authorization and approval procedures should be explicit; (3) information system should establish access security systems and there should be definite regulations for operating authority, information usage and information management; (4) hardware management and its examination and approval procedures should be scientific and rational; (5) accounting computerization process should be normative, and the operation management of accounting computerization, the management of hardware, software and data, the archive management of accounting computerization and the financial management of accounting computerization should be optimized. On the basis of the abovementioned measures, the specific measures for the internal control of accounting information system amid the ERP environment can be categorized as follows: organization control, management system control, control over system development and maintenance, control over system's operational security, application control, control over data security, control over network security, and archive management.

D. Information and communication

Information and communication refers to the process of promptly, accurately and comprehensively gleaning the various information related to the corporate operation and management and allowing the information to be disseminated promptly, communicated effectively and applied properly. It is a crucial condition for implementing internal control. Information and communication primarily comprises information-collecting mechanism and communication mechanism in relevant aspects both inside and outside of the enterprise. Accounting information system amid the ERP environment boasts the characteristics of availability, real-time feedback and computerization. Different departments in the enterprise can share a unified data platform, which helps realize the integrated management of various business procedures, and information demanders can acquire sundry information in real time. The relatively open information system also provides open communication channel for internal staff and managers, which facilitates the internal communication and allows the staff within the organization to clearly understand the internal control system and their respective responsibilities. Managers can also obtain the information at any time regarding the implementation and entry into force of the internal control system. However, an open technical environment is rarely immune to illegal invasion and the system is also at risk of being visited illegally and even being sabotaged.

\section{Conclusion}

The development of internal control boasts a long history, but it is still a topical issue in present-day theoretical and practical realms. With the extensive application of ERP system in enterprises, accounting information system has already been incorporated into ERP. This paper studies the establishment of internal control of accounting information system amid the ERP environment by dint of integrating ERP and internal control of accounting information system. It also studies the implementation of internal control of accounting information system in line with the characteristics of ERP and accounting information system. The purpose of this paper consists in helping enterprises raise risk awareness in constructing accounting information system, meticulously formulate internal control systems in accordance with their own development, implement corresponding control measures without any reservation, and thus do their utmost to ensure the authenticity and accuracy of the accounting information.

\section{References}

[1] The Committee of Sponsoring Organizations of the Tread way Commission. Internal Control 
Integrated Framework (the COSO report).

[2] Integrating internal control in MBA programmes using the COSO and CoCo models [J]. Irene M. Herremans. Managerial Auditing Journal. 1997 (2)

[3] Risk management: The reinvention of internal control and the changing role of internal audit[J] . Laura F. Spira,Michael Page. Accounting, Auditing \& Accountability Journal. 2003 (4)

[4] Enterprise Risk Management Integrated Framework. Committee of Sponsoring Organizations of the Treadway Commission(COSO). . 2004

[5] Enterprise resource planning: A taxonomy of critical factors[J] . Majed Al-Mashari,Abdullah Al-Mudimigh,Mohamed Zairi. European Journal of Operational Research. 2002 (2) 